\section{Original} Article

\begin{tabular}{l}
\hline Access this article online \\
\hline Website: \\
http://ajobe.journals.ac.za/ \\
\hline DoI: \\
http://dx.doi.org/10.15249/6-1-8 \\
Quick Response Code: \\
\hline
\end{tabular}

Address for correspondence: Prof. Adèle Thomas,

Department of Industrial Psychology and People Management, University of Johannesburg, P.O. Box 524, Auckland Park, 2006, South Africa. E-mail: adelet@uj.ac.za

\title{
Student academic dishonesty: What do academics think and do, and what are the barriers to action?
}

\author{
Adèle Thomas, Gideon P. De Bruin
}

Department of Industrial Psychology and People Management, University of Johannesburg, Auckland Park, South Africa

ABSTRACT

The aims of the study were to explore the awareness of and attitudes towards student academic dishonesty at a South African university, and to explore perceived personal and institutional barriers to taking action against such dishonesty. All full-time academic staff at the University of Johannesburg were anonymously surveyed during late 2009. The findings indicated a high level of awareness of student academic dishonesty, with few faculty members taking action against it. Four groups of barriers to preventing and acting on student academic dishonesty were identified, with two of these barrier groups being significantly related to willingness to report student academic dishonesty.

Key words: Faculty actions, Institutional barriers, Personal barriers, Prevention, South Africa

\section{INTRODUCTION}

Locally and internationally, student academic dishonesty is on the increase (Elander, Pittam, Lusher, Fox and Payne, 2010; Martin, Rao and Sloan, 2009), and it can be expected that dishonest students will carry forward this unethical behaviour as leaders and employees. Accordingly, as a means of contributing to a greater ethical society, universities should be taking steps to address and curb student academic dishonesty (Garofalo, 2003).

There appears to be a lack of concerted action on the part of university faculty to address student academic dishonesty (Teodorescu and Andrei, 2009), in spite of the amount of academic literature that exists detailing the nature and the extent of this problem. Accordingly, the objectives of the present study were to:

- Investigate the awareness of and attitudes towards student academic dishonesty on the part of faculty at a leading South African university.

- Investigate the actions (prevention and follow-through) that faculty take to address student academic dishonesty.

- Identify perceived personal and institutional barriers leading to avoidance of action by faculty to prevent and address student academic dishonesty.
The overall research question that served as a context for the study was: What do academics think and do about student academic dishonesty, and what are the barriers to action?

The present study contributes to theory in this field by focusing specifically on academic attitudes and responses to student academic dishonesty rather than on student academic dishonesty itself, which has received extensive coverage in international literature and, to a lesser extent, in South African literature. In this vein, Hard, Conway, and Moran (2006) suggest that there is little theoretical or empirical literature that relates directly to faculty beliefs about student academic misconduct, and Coalter, Lim, and Wanorie (2007) note the limited research on factors that influence faculty actions to address student dishonesty. Specifically in Africa, Gbadamosi (2004) notes the dearth of research on cheating in the academic arena. Valentine and Kidwell (2008) also advocate research to provide insight into the manner in which faculty view their own ethical behaviour, which, it can be argued, manifests in the way in which they deal with student academic dishonesty. Parameswaran and Devi (2006, p. 271) note that non-action by faculty in addressing this problem allows "faculty negligence [to] remain an 'invisible crime' 
[and to] contribute to its [student academic dishonesty] proliferation."

\section{Institutional responses to student academic dishonesty}

Cheating during tests, plagiarising, buying assignment papers, falsifying data, using dishonest excuses, getting others to take examinations, misusing resources, and manipulating academic staff can all be regarded as acts of academic dishonesty (Park, 2003). Academic dishonesty among students has been noted to be rising in South Africa (De Bruin and Rudnick, 2007), in line with the international trend (cf. Lahm, 2007; Lee, 2009). Furthermore, past cheating behaviour is a reliable predictor of future cheating (Martin et al., 2009).

Strategies to address student academic dishonesty by universities have included orientating students to academic rules, enforcement policies, and penalties (Hutton, 2006), reiterating such policies to faculty members (Hutton, 2006), publishing policies regarding academic dishonesty in course syllabi (Kiehl, 2006), utilising creative pedagogic teaching and examination methods to minimise the chances of dishonesty (Born, 2003), informing students about what constitutes academic dishonesty (Brown, Dickson, Humphreys, McQuillan and Smears, 2008), developing honour codes for institutions or codes of conduct specifically for students (Cooper and Schwartz, 2007) and having students sign codes of conduct (Warren and Rosenthal, 2006). There is evidence that suggests that publicising and imposing potential penalties reduce the incidence of student academic misconduct (Bisping, Patron and Roskelley, 2008; Lee, 2009).

Volpe, Davidson, and Bell (2008) suggest that universities and their faculty tend to underestimate the prevalence of student academic dishonesty, possibly due to the ease of cheating by means of advanced technology, and Smith-Gratto and Jost (2007) state that faculty appear reluctant to report such misconduct. Eastman, Iyer and Eastman (2006) suggest that students, faculty, and administrators know that student academic dishonesty is occurring, but that little is done to stop it.

Schmelkin, Gilbert, Spencer, Pincus, and Silva (2008) note that faculty failure to take action to discipline student academic dishonesty influences students' understanding of academic standards. Student dishonesty has also been shown to increase where faculty are known to be lenient towards cheaters (Lee, 2009), where the perceived probability by the student of being caught is low, along with leniency in subsequent punishment $\left(\mathrm{O}^{\prime}\right.$ 'Rourke, Barnes, Deaton, Fulks, Ryan and Rettinger, 2009), and when there is the opportunity to cheat (Rawwas and Isakson, 2000). Mullins (2000, p. 26) adds that failure to address student academic dishonesty conveys the message that "a core value of academic life, honesty, is not worth any significant effort to enforce." Similarly, Robinson, Amburgey, Swank, and Faulkner (2004, p. 382) note that professorial conduct can "augment or dampen" student cheating, and Hughes and McCabe (2006) stress the critical role of faculty in creating an institutional context that encourages integrity.

Some of the personal and institutional reasons advanced to explain faculty's reluctance to address student academic dishonesty include: denial of the problem (Staats, Hupp, Wallace and Gresley, 2009); lack of faculty buy-in to formal policies and procedures (Hughes and McCabe, 2006); perceptions by faculty members that procedures to address student dishonesty are too cumbersome (Hughes and McCabe, 2006); inconsistent and sporadic enforcement of ethics policies (Williams and Hosek, 2003); inappropriate penalties (Hughes and McCabe, 2006); perceived time and effort required of faculty in a system that primarily rewards research (Puka, 2005); faculty being overburdened by teaching, committee, and publishing responsibilities (Coalter et al., 2007) and teaching large classes, leading to difficulties in monitoring academic misconduct (Bertram-Gallant, 2008); potential personal costs to the faculty in confronting a dishonest student and possible associated litigation, and harassment or blame by the administration for the situation (Staats et al., 2009); a perception amongst faculty that they, instead of the dishonest students, become the defendants (Thompson, 2006); unwillingness of faculty to play the role of 'cop' and engage in confrontation (Larkham and Manns, 2002); a lack of evidence/proof of dishonesty (Staats et al., 2009), or fear of an inability to substantiate claims (Brimble and Stevenson-Clarke, 2006). Bertram-Gallant (2007; 2008) stresses that a lack of institutional support for faculty who take disciplinary action against student academic dishonesty contributes to their reluctance to pursue identified transgressions. Bertram-Gallant (2008) further believes that faculty's expectation of promotion due to good teaching ratings by students conflicts with reporting and pursuing cases of student dishonesty.

\section{Institutional culture}

Puka (2005) suggests that faculty themselves do not introspect with regard to their own forms of unethical academic behaviour, such as cheating and plagiarising, thereby creating a climate that is not conducive to academic integrity. Similarly, Bartlett and Smallwood (2004: A8) suggest that very few cases of academic dishonesty by faculty are ever "dragged into the sunlight ... because the academy often discourages victims from seeking justice, and when they do, tends to ignore their complaints - a kind of scholarly 'don't ask, don't tell' policy."

Furthermore, studies indicate that academic dishonesty by faculty members may negatively interfere with the student learning process as well as with the work environment of 
their colleagues (Borkowski and Welsh, 1998; Lewellyn, 1996; Robie and Kidwell, 2003). Bertram-Gallant (2008: 74) suggests that "academic capitalism" has contributed to "academic fraud" in that commercial interests, funding, and enrolment numbers command greater faculty attention, which negatively impacts on student development and learning. Instead of students viewing faculty as teachers, they are regarded as producers of knowledge in order to achieve ranking and prestige. In this regard, Bok (2003: 109) notes that students are unlikely to follow "espoused principles of academic integrity if they perceive that the institution compromises its own moral principles in order to ... sign a lucrative research contract, or earn a profit from Internet courses ... [U]ndergraduates often learn more from the example of those in positions of authority than they do from lectures in the classroom".

In summary, the literature above suggests an increase in student academic dishonesty internationally, in spite of individual faculty and institutional responses to the problem. Clearly, this is an area that should command on-going research interest

\section{MATERIALS AND METHODS}

\section{Research approach}

A quantitative survey was employed to examine the perceptions of full-time faculty with regard to student academic dishonesty and the personal and institutional barriers to prevention and action.

\section{Participants}

All full-time academic faculty employed by the University of Johannesburg $(N=917)$ (University of Johannesburg, 2008) were surveyed during July 2009. A total of 450 academics $(49 \%)$ returned the questionnaires, which, in the main, were complete. However, it should be noted that not every participant responded to all the questions; however, no more than $5 \%$ of the responses for any of the variables were missing, with the majority of the missing data for any single variable, on average, amounting to less than $2 \%$.

Due to the sensitive nature of the topic, the researchers avoided requesting biographic and demographic details that could be perceived as information that could identify individual participants, particularly as the researchers themselves are academics at the university. Hence, no information with respect to age, gender, race, and tenure with the university was collected.

\section{Method of data gathering}

Data were collected by means of a questionnaire that was informed by the literature review. The questionnaire comprised four sections. Section 1 sought to gain information about the attitudes of participants with regard to student academic dishonesty. Participants indicated their agreement or disagreement with nine statements on a five-point Likert-type scale. A sample statement is: "There are no excuses to justify academic cheating among students."

The 18 items of Section 2 aimed to solicit participants' views with regard to personal and institutional barriers when dealing with student academic dishonesty. Again, a five-point Likert-type scale was utilised, but with an additional response category where participants could indicate whether they were unable to express agreement or disagreement with any particular statement. A sample item is: "Academics who report student academic dishonesty can expect to be supported by the institution."

Section 3 focussed on the actions of academics in response to student academic dishonesty. Participants responded to six questions on a five-point Likert-type scale to indicate the extent of their own actions and their perceptions of institutional actions with regard to student academic dishonesty. A sample item is: "To what extent are you willing to report student academic dishonesty, should you detect it?"

The final section contained five questions, where participants were required to estimate the prevalence (in percentage terms) of (a) students engaging in academic dishonesty at least once during their academic careers, (b) students regularly engaging in academic dishonesty, (c) faculty members engaging in some form of academic dishonesty, (d) faculty members taking active steps to prevent student academic dishonesty, and (e) faculty members taking active steps against identified student academic dishonesty.

\section{Procedure}

The study proposal, including the questionnaire, was cleared by the ethics committee of the university. The deans of each faculty gave permission for their academic staff to be surveyed. In communications with prospective participants through the deans, faculty were assured of voluntary and anonymous participation. Questionnaires were distributed to all full-time faculty members by research assistants, along with envelopes in which completed questionnaires could be sealed, thereby ensuring the participants' anonymity. The sealed envelopes were collected from participants by the research assistants or could be sent anonymously to the researchers through the university's internal mail system.

\section{Analysis of data}

The data analysis commenced with an inspection of the frequency of responses in the different categories of the questionnaire. In addition, a principal components analysis using oblique Direct Quartimin rotation was performed on the data relating to barriers to academic action. These 
barrier components were related to faculty's willingness to report student academic dishonesty through the use of discriminant function analysis.

\section{RESULTS}

\section{Perceptions of prevalence of student academic dishonesty}

Sixty-six per cent of the participants indicated that they had reported student academic dishonesty at some point in their academic careers. In addition, 84.4\% stated that they would report such behaviour if they detected it, and $69.0 \%$ believed that their colleagues take student academic dishonesty seriously. With respect to the academic dishonesty of colleagues, participants estimated, on average, that approximately $10 \%$ of faculty themselves engage in some form of academic dishonesty $(\operatorname{mode}=10 \%)$.

The awareness of student academic dishonesty was further explored by examining the perceptions of participants about the prevalence of such dishonesty. Participants were firstly required to indicate the percentage of students they believed engage in academic dishonesty at least once during their (student) academic careers, and then to indicate their estimation of the percentage of students who regularly engage in academic dishonesty.

Figure 1 indicates that participants held widely diverging perceptions regarding the prevalence of at least one incident of academic dishonesty during a student's academic career. The modal estimate was $10 \%$, but some participants believed that all students are dishonest at some point.

In contrast, some participants estimated a lower prevalence of students engaging in regular acts of academic dishonesty [Figure 2].

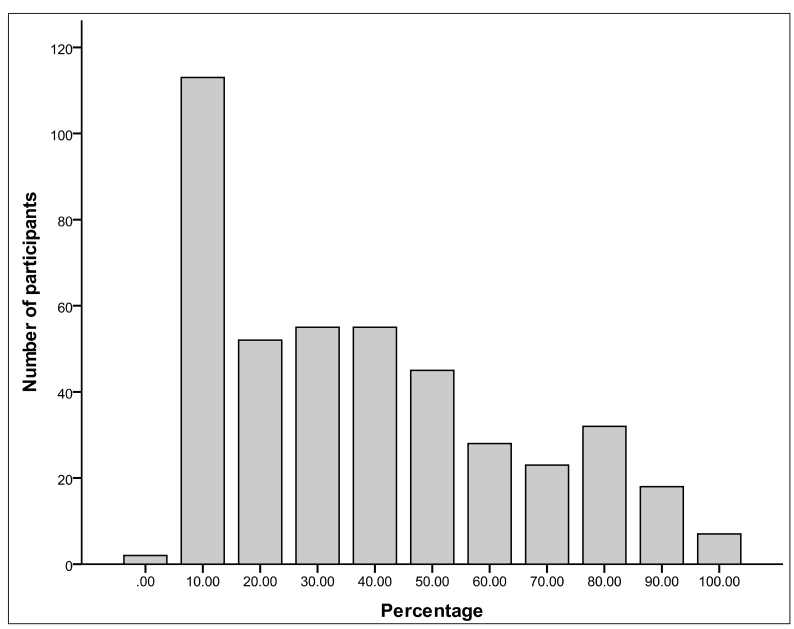

Figure 1: Percentage of students who engage in academic dishonesty at least once during academic career
Participants' attitudes towards student academic dishonesty

From Table 1 it can be seen that, overall, participants acknowledged the seriousness of student academic dishonesty and the role that they as faculty play in influencing students' moral development. For instance, $92.6 \%$ of the participants agreed that student academic dishonesty poses a serious threat to the academic ideals of the university (item 1). Furthermore, $85.0 \%$ agreed that they should make special efforts to prevent student academic dishonesty (item 2). In addition, $87.8 \%$ of the participants agreed that it is part of their job to help students learn ethical behaviour (item 3). However, attitudes towards the severity of punishment for transgressors were mixed and inconsistent (item 4). Whereas the single largest category of participants (45.5\%) agreed that academic cheaters should be expelled from the university, even if it was their first offence, $29.8 \%$ disagreed, and a relatively high proportion $(24.7 \%$ ) were ambivalent regarding the severity of punishment for student cheaters.

It should be noted, that a non-negligible proportion of participants appeared not to be concerned about student academic dishonesty and appeared to suggest that academics have little responsibility for addressing this issue. For example, $8.3 \%$ of the participants disagreed that faculty should make special efforts to prevent student academic dishonesty (item 2), and 6.1\% did not believe that it was the role of faculty to help students learn ethical behaviour (item 3).

\section{Perceptions of prevention and action by faculty} members regarding student academic dishonesty Whereas Figures 1 and 2 illustrate that participants were aware of the incidence of student academic dishonesty, Figures 3 and 4 reflect the perceptions of participants about faculty prevention of and action against such dishonesty. With regard to perceptions about the prevention of student academic dishonesty, a bimodal distribution was observed (mode $1=10 \%$; mode $2=80 \%$ ), reflecting widely diverging

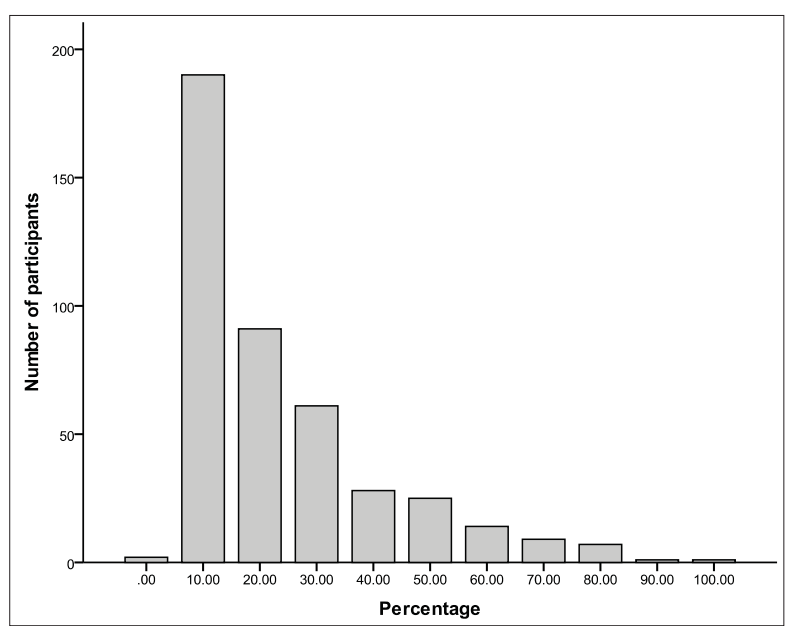

Figure 2: Percentage of students who regularly engage in academic dishonesty 
views. On the whole, however, Figure 3 illustrates that most participants believed that their colleagues take active steps to prevent student academic dishonesty.

However, Figure 4 illustrates that participants perceived fewer of their colleagues as actively following through in addressing student academic dishonesty. Note, however, that largely diverging perceptions of follow-through actions were indicated.

In the section that follows, the focus falls on the specific steps that participants themselves take to prevent student academic dishonesty in their own courses.

From Table 2, it can be seen that participants appeared to appreciate the importance of taking steps to prevent student academic dishonesty. The majority $(58.4 \%)$ indicated

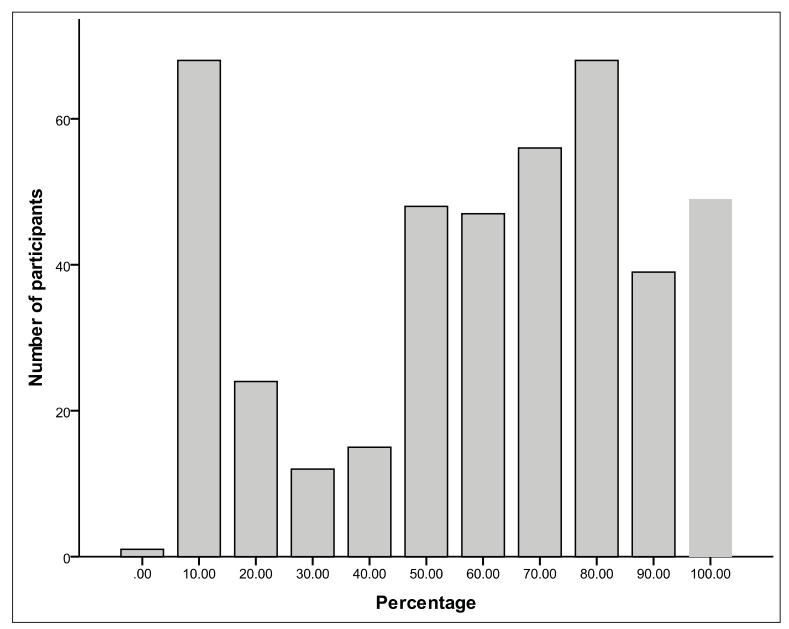

Figure 3: Percentage of faculty perceived to take steps to prevent student academic dishonesty

\begin{tabular}{lccc}
\hline Table 1: Participants' attitudes toward student academic \\
dishonesty
\end{tabular}

that they actively discuss the consequences of academic dishonesty (item 1) and how it will be dealt with $(56.7 \%$; item 2) with their students, and that they explicitly address academic dishonesty in their course materials $160.8 \%$; item 3). However, a sizable proportion of participants $(15.5 \%)$ rarely engage in discussion with students about the negative consequences of academic dishonesty (item 1) and how it will be dealt with (19.6\%; item 2$)$, and there are no specific sections in their study material that deal with academic dishonesty (18.5\%; item 3 ). Table 2 also indicates that a relatively large proportion of participants (ranging from about 20\% to 26\%) applied their prevention strategies inconsistently.

\section{Barriers to addressing student academic dishonesty}

The perceptions of participants were examined with regard to existing barriers that could account for a lack of follow-through in addressing student academic dishonesty.

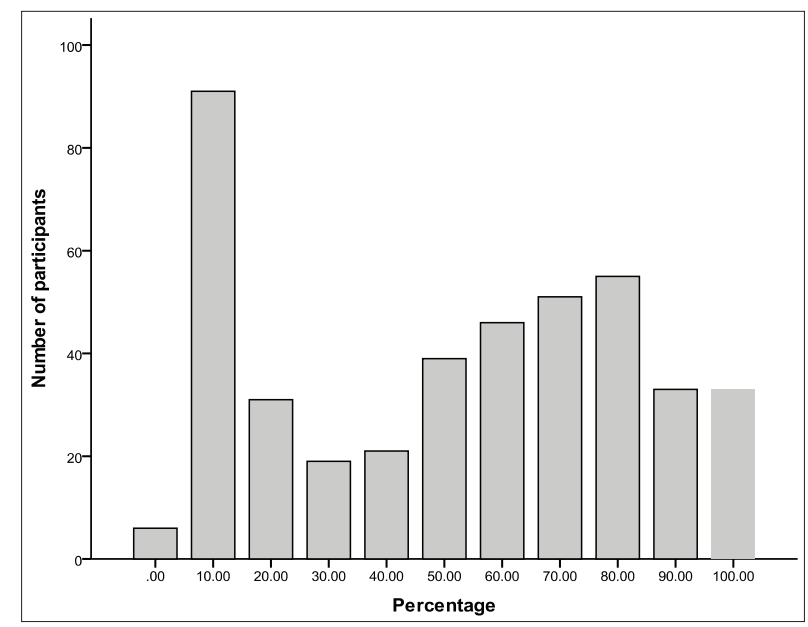

Figure 4: Percentage of faculty perceived to take action to address student academic dishonesty

Table 2: Participants' actions toward preventing student academic dishonesty

\begin{tabular}{|c|c|c|c|c|}
\hline \multirow[t]{2}{*}{ Item } & & \multicolumn{3}{|c|}{ To a limited To some To a great } \\
\hline & & \multicolumn{3}{|c|}{ Percentage } \\
\hline 1. & $\begin{array}{l}\text { To what extent do you } \\
\text { make a point of discussing } \\
\text { with your students the } \\
\text { negative consequences of } \\
\text { academic dishonesty? }\end{array}$ & 15.5 & 26.1 & 58.4 \\
\hline 2. & $\begin{array}{l}\text { To what extent do you } \\
\text { make a point of discussing } \\
\text { with your students how } \\
\text { you will deal with academic } \\
\text { dishonesty in your course? }\end{array}$ & 19.6 & 23.8 & 56.7 \\
\hline 3. & $\begin{array}{l}\text { To what extent does your } \\
\text { study guide/curriculum } \\
\text { contain an explicit section } \\
\text { dealing with academic } \\
\text { dishonesty? }\end{array}$ & 18.5 & 20.8 & 60.8 \\
\hline
\end{tabular}


Table 3 contains a list of 18 potential institutional and personal barriers. Rather than analysing the individual barriers, the data were subjected to a principal components analysis with the aim of identifying groups of items that represented broader themes. Participants indicated their agreement or disagreement with each of the items on a three-point scale (agree, sometimes agree/disagree, disagree) but, in recognition of the fact that some participants may not have had enough work experience to meaningfully respond to some items, the category "I don't know" was provided. These responses were not included in the principal components analysis.

Four interpretable components, which jointly accounted for approximately $51 \%$ of the observed variance, were identified and rotated according to the Direct Quartimin criterion. To facilitate interpretation of the components, the items in Table 3 were ordered to correspond with the order of the components that they defined.

The first component was defined by items 1 to 9, which reflected psychological barriers associated with emotional discomfort of (i.e. fear of not having enough evidence prevents lecturers from dealing with student academic dishonesty) and cost of addressing student academic dishonesty (i.e. the effort required to deal with students suspected of academic dishonesty is too great to make it worthwhile). The second component was defined by items 10 to 13 , which represented barriers that relate to institutional procedural clarity in addressing student academic dishonesty (i.e. whether the university has clear policies with respect to the definition of academic dishonesty). The third component was defined by items 14 to 16, which represented barriers associated with perceived social and institutional support for faculty who address student academic dishonesty (i.e. whether faculty who report student academic dishonesty can expect to be supported by their colleagues/peers). The fourth component was defined by items 17 and 18, which represented barriers that relate to the ease with which students can cheat in exams and assignments.

Table 4 indicates the extent to which participants agreed with, disagreed with, or were unable to express an opinion about the items that relate to each barrier component. Within each component, an average was calculated for each of the response categories of the items defining that component.

\section{Component one (Psychological discomfort and personal cost)}

On average, $23.7 \%$ of the participants agreed that the psychological effort and cost factors represented by component one presented an obstacle to preventing and acting on student academic dishonesty, and $20.1 \%$ sometimes regarded it as an obstacle. In contrast, 51.6\% did not regard psychological discomfort and cost as an obstacle. This indicates that, on
Table 3: Direct Quartimin rotated component pattern matrix of barrier items

Item Component

1. The effort required to deal with students suspected of academic dishonesty is too great to make it worthwhile

2. Dealing with the red tape is so unpleasant that sometimes it would be better to let student cheating go than act on it

3. Academic workload prevents lecturers 0.55 from following through on student academic dishonesty

4. Fear of developing a negative reputation among students prevents lecturers from dealing with student academic dishonesty

5. Fear of not having enough evidence prevents lecturers from dealing with student academic dishonesty

6. Fear of litigation prevents lecturers from dealing with student academic dishonesty

7. University focus on student throughput prevents lecturers from dealing with student academic dishonesty

8. The extra time required to structure assessment opportunities to minimise student academic dishonesty discourages lecturers from doing this

9. Fear of harming students who unwittingly commit acts of academic dishonesty prevents lecturers from dealing with student academic dishonesty

10. The university has clear policies with respect to the definition of academic dishonesty

11. The university has clear guidelines on how lecturers should act when students are suspected of academic dishonesty

12. The university has efficient procedures in dealing with students who are accused of academic dishonesty

13. Students are adequately informed about what constitutes academic dishonesty

14. There are adequate resources available at the university to detect student academic dishonesty

15. Academics who report student academic dishonesty can expect to be supported by their colleagues/peers

16. Academics who report student academic dishonesty can expect to be supported by the institution

17. It is easy for students to cheat in

18. It is easy for students to cheat in assignments 
Table 4: Perceived personal and institutional barriers to addressing student academic dishonesty

Item

I don't know Disagree Sometimes agree,/disagree Agree

Percentage

Component 1 (Barriers related to psychological discomfort and cost of addressing student academic dishonesty)

1. The effort required to deal with students suspected of academic dishonesty is too great to make it worthwhile

2. Dealing with the red tape is so unpleasant that sometimes it would be better to let student cheating go than act on it

3. Academic workload prevents lecturers from following through on student academic dishonesty

4. Fear of developing a negative reputation among students prevents lecturers from dealing with student academic dishonesty

5. Fear of not having enough evidence prevents lecturers from dealing with student academic dishonesty

6. Fear of litigation prevents lecturers from dealing with student academic dishonesty

7. University focus on student throughput prevents lecturers from dealing with student academic dishonesty

8. The extra time required to structure assessment opportunities to minimise student academic dishonesty discourages lecturers from doing this

9. Fear of harming students who unwittingly commit acts of academic dishonesty prevents lecturers from dealing with student academic dishonesty

Mean

Standard deviation

Component 2 (Barriers related to institutional procedural clarity)

10. The university has clear policies with respect to the definition of academic dishonesty

11. The university has clear guidelines on how lecturers should act when students are suspected of academic dishonesty

12. The university has efficient procedures in dealing with students who are accused of academic dishonesty

13. Students are adequately informed about what constitutes academic dishonesty

Mean

Standard deviation

Component 3 (Barriers related to social and institutional support)

14. There are adequate resources available at the university to detect student academic dishonesty

15. Academics who report student academic dishonesty can expect to be supported by their colleagues/peers

16. Academics who report student academic dishonesty can expect to be supported by the institution

Mean

Standard deviation

5.3

4.5

3.6

2.7

4.0

7.1

4.7

6.0

2.7

6.5

0.7

6.0

5.8

8.5

5.8

6.7

1.3

7.8

4.2

5.4

5.8

1.5

Component $\mathbf{4}$ (Barriers related to ease of student cheating)

17. It is easy for students to cheat in exams

18. It is easy for students to cheat in assignments

Mean

Standard deviation
52.1

60.1

15.5

14.5

22.9

19.9

17.9

25.0

58.4

22.5

51.6

20.1

23.7

11.2

3.6

8.1

\section{9}

8.7

73.5

.8

16.5

13.8

26.7

23.4

41.3

14.5

15.6

64.0

17.4

15.4

60.7

3.2

3.0

6.8

7.8

44.5

21.0

26.8

9.6

15.8

70.4

.4

20.9

18.8

54.9

25.0

18.5

50.7

14.5

2.1

18.0

$\begin{array}{lccc}2.7 & 38.5 & 26.0 & 32.8 \\ 0.9 & 6.1 & 15.7 & 77.4 \\ 1.8 & 22.3 & 20.9 & 55.1 \\ 0.9 & 16.2 & 5.15 & 22.3\end{array}$

average, a sizable proportion of participants (about 43\%) regarded these psychological factors as a barrier at least on some occasions. Inspection of the individual barriers defining component one indicates that workload, in particular, was seen as the most salient barrier (item 3), followed by fear of not having enough evidence to successfully follow through on cases of student academic dishonesty (item 5), and, thereafter, the extra time required to structure assessment opportunities to prevent cheating (item 8).

\section{Component two (Institutional procedural clarity)}

Responses to the items defining component two suggest that the majority of participants $(60.7 \%)$ did not perceive institutional policies to be a barrier to preventing and acting 
on student academic dishonesty, but $17.4 \%$ did regard such policies as barriers, and $15.4 \%$ regarded institutional policies as a barrier some of the time. Overall, participants regarded the lack of efficient procedures to deal with dishonest students as the most salient institutional barrier associated with this component (item 12). In support of this finding, a separate question that explored views on consistent treatment of student academic dishonesty revealed that $74.8 \%$ of participants believed that the university is less than consistent in addressing this matter.

\section{Component three (Social and institutional support)}

Only $50.7 \%$ of the participants agreed that they have social and institutional support and resources to follow through on identified cases of student academic dishonesty, with $25.0 \%$ disagreeing, and $18.5 \%$ indicating that a lack of social and institutional support presented barriers at least some of the time. Collegial support (item 15) appeared to present less of a problem than did the lack of available resources (item 14) and the lack of institutional support (item 16). Responses to item 14 indicated that the availability of resources to detect student academic dishonesty presented a real barrier in dealing with such dishonesty.

\section{Component four (Ease of student cheating)}

The ease with which students can cheat in examinations and assignments was regarded as a barrier to action by $55.1 \%$ of the participants (possibly reflecting a resignation that not much could be done about the problem). Note, however, that widely divergent views were held with respect to the ease with which students can cheat in exams on the one hand (item 17) and assignments on the other (item 18), with assignments perceived as being more vulnerable to cheating.

Component scores were calculated for each of the four barrier components, using the regression method (cf. Gorsuch, 1983). Table 5 displays the means of two groups of faculty, namely those who indicated that they will report student academic dishonesty in the future if they encounter this problem $(\mathrm{n}=373)$, and those who indicated that they will not do so $(\mathrm{n}=69)$. Univariate $t$-tests showed that the two groups differed significantly $(P<0.05)$ on two of the barrier components, namely psychological discomfort and personal cost, and procedural clarity. Discriminant function analysis showed that the relationship between the four barrier components and willingness to report student academic dishonesty was statistically significant [Wilk's $\Lambda=0.90, \chi^{[2]}$ $(4)=42.62, P<0.001]$. The linear combination of the four barrier components jointly accounted for approximately $10 \%$ of the variance in willingness to report student academic dishonesty. The correlations between each of the four barrier components and the discriminant function were as follows: Psychological discomfort and cost $(r=0.86)$, procedural clarity $(r=-0.54)$, social and institutional support $(r=-0.13)$, and ease of cheating $(r=-0.024)$. These results, in conjunction with the means reported
Table 5: Descriptive statistics for barrier components in relation to willingness to report student academic dishonesty

\begin{tabular}{|c|c|c|c|c|c|}
\hline \multirow[t]{2}{*}{ Barrier component } & \multicolumn{2}{|c|}{$\begin{array}{l}\text { Unwilling } \\
\text { to report } \\
\text { (n=69) }\end{array}$} & \multicolumn{2}{|c|}{$\begin{array}{l}\text { Willing to } \\
\text { report } \\
(n=373)\end{array}$} & \multirow[t]{2}{*}{$\begin{array}{c}t \\
(424)\end{array}$} \\
\hline & Mean & SD & Mean & SD & \\
\hline $\begin{array}{l}\text { Psychological discomfort and } \\
\text { cost }\end{array}$ & 0.64 & 0.94 & -0.11 & 0.96 & $5.81^{*}$ \\
\hline Institutional procedural clarity & -0.40 & 1.01 & 0.08 & 0.97 & -3.61 \\
\hline Social and institutional support & -0.09 & 1.11 & 0.03 & 0.97 & -0.87 \\
\hline Ease of student cheating & -0.02 & 0.91 & 0.00 & 1.02 & -0.16 \\
\hline
\end{tabular}

$* P<0.05$

in Table 5, indicate that participants who expect high levels of psychological discomfort and personal cost on the one hand, and perceive a lack of procedural clarity on the other hand, appear less willing to report student academic dishonesty should they encounter it than do those who do not perceive these issues to be barriers. Perceptions of social and institutional support, as well as the ease with which students can cheat, appear not to be associated with willingness to report student academic dishonesty.

\section{DISCUSSION}

Student academic dishonesty is on the increase internationally. In order for universities to exercise their mandate and influence students' moral development (Conroy and Emerson, 2004), it is essential that the problem of student academic dishonesty is addressed (Lee, 2009). Dishonest students will also carry forward dishonest behaviour into society. Against this background, the objectives of the present study were to:

- Investigate the awareness of and attitudes towards student academic dishonesty on the part of faculty at a leading South African university.

- Investigate the actions (prevention and follow-through) that faculty take with regard to student academic dishonesty.

- Identify perceived personal and institutional barriers leading to avoidance of action by faculty in preventing and addressing student dishonesty.

The discussion of the findings occurs against the backdrop of these three specific objectives.

Generally, the participants were aware of student academic dishonesty being perpetrated within the university. However, participants held vastly divergent perceptions with regard to both single acts of student transgressions and more regular dishonest behaviour, which may indicate a lack of general awareness of the problem within the university as a whole. In this regard, Eastman et al. (2006) and Volpe et al. (2008) note that the prevalence of student dishonesty is often underestimated by faculty, one explanation for 
this being that universities have become cumbersome, bureaucratic organisations.

The majority of participants acknowledged the seriousness of student academic dishonesty and the role that they can play in addressing this issue (Table 1). However, a non-negligible proportion of participants was seemingly ambivalent about the problem $(7.4 \%$, item 1$)$, and appeared to suggest that faculty have little responsibility for addressing this matter, echoing the findings of Schmelkin et al. (2008) who note the apparent lack of concern by faculty about this assault on academic values. In addition, participants were of the opinion that $10 \%$ of faculty themselves engage in dishonest academic behaviour.

Over $60 \%$ of participants had reported incidents of student academic dishonesty at some time in their academic careers, of whom $80 \%$ appeared willing to continue reporting such dishonesty. In seeming contradiction however, faculty appeared to be more willing to take preventive steps to deter student academic dishonesty than they were to take action against such dishonesty (compare Figures 3 and 4). This finding may reflect the intention to report student academic dishonesty, but that actual follow-through action against perpetrators is lacking, echoing the findings reported by Schmelkin et al. (2008) and Smith-Gratto and Jost (2007). This disinclination to act could be due to a lack of clear directives and explicit procedures within departments and faculties, although the university as a whole may have established such policies and procedures, as noted by participants (Table 4, items 10 and 11). Acts of prevention, on the other hand, may fall within the locus of control of individual faculty and, as such, are less dependent upon the vagaries of the system.

Faculty appear to be more inclined to take steps to prevent student academic dishonesty than to act on such incidents. Nevertheless a non-negligible number still reported taking action only "to some extent." Kidwell, Woziak, and Laurel (2003) stress the importance of developing an understanding in students of the consequences of dishonesty, and Brown et al. (2007) strongly advocate the training of students in awareness of the nature of academic dishonesty. As a preventive measure, Bisping et al. (2008) suggest that publicising potential penalties for student academic dishonesty impacts positively on the reduction thereof.

The principal components analysis revealed four groups of barriers to faculty members preventing and acting on student academic dishonesty namely (a) psychological discomfort and personal cost, (b) institutional procedural clarity, (c) social and institutional support, and (d) ease of student cheating.

Participants reported that the most important barriers relating to the psychological discomfort and cost of addressing student dishonesty included: high workloads, additional time needed to structure assignments to minimise dishonesty, and having insufficient evidence to progress action against students. Bertram-Gallant (2008) notes how the pressures on faculty to be exceptional teachers and extensively engage in research compete with the lesser-rewarded activity of addressing student academic dishonesty. Similarly, Coalter et al. (2007) note that the opportunity costs associated with pursuing such dishonesty are often too great for faculty, especially when coupled with the additional stress caused by action against student perpetrators.

When considering barriers relating to institutional procedural clarity, participants generally reported that the university has clear policies relating to academic dishonesty, together with guidelines that faculty members can follow in addressing errant behaviour, and that students are adequately informed about what constitutes student academic dishonesty. The most important barrier in this overall component appears to be the lack of efficient procedures in dealing with student academic dishonesty, linked to perceived inconsistency on the part of the university in dealing with students who have been reported as transgressors.

If the main barriers regarding social and institutional support are taken into account, it appears that the lack of adequate resources is the single largest barrier to addressing student academic dishonesty. This finding, coupled with the identification of inefficient procedures and inconsistent treatment of student transgressors (as noted above), paints a picture of institutional barriers that require attention if faculty are expected to proactively address student academic dishonesty. These findings appear, again, in seeming contradiction to those that indicated that faculty acknowledge the existence of sound overall university policies and guidelines relating to student academic dishonesty (Table 4, items 10 and 11). It is suggested that, possibly, policies and guidelines have not filtered down to faculty level, an explanation that could also cast light on the mixed and inconsistent views expressed by participants regarding the severity of punishment for student offenders. Coalter et al. (2007) state that faculty often disagree about the fairness and impartiality of processes of dealing with student academic dishonesty. Kidwell et al. (2003) stress the importance of faculty consistency in this regard, and Williams and Hosek (2003) also warn that inconsistent implementation of ethics policies at universities can negatively impact attempts to address student academic dishonesty.

Participants tended to believe, however, that while institutional resources to address student academic dishonesty are lacking, those who do report such dishonesty can expect to be supported by their colleagues and, to a lesser extent, by the institution as a whole. 
Volpe et al. (2008) and Lehobye (2010) report that advanced technology enables students to cheat more easily. When considering the barrier component relating to ease of student cheating, participants reported greater ease of cheating in assignments than in examinations. Taking action in this area demands that faculty structure assessment opportunities that make cheating more difficult (Kiehl, 2006). Lee (2009) recommends that unique features that minimise plagiarism be built into assignments. However, typically, such action would involve additional faculty time to redesign assessment opportunities and evaluate the work, thereby increasing their workload, which has already been noted as a barrier to addressing student dishonesty.

While the literature appears to support the findings of the present study with regard to the four barrier components that impact prevention and action, discriminant analysis revealed that only two barrier components (psychological discomfort and cost, and institutional procedural clarity) meaningfully impact willingness to report student academic dishonesty. Inspection of the content of the psychological discomfort and cost component suggests the presence of two facets, namely volume of workload (including issues such as bureaucracy, pressures relating to student throughput, and work overload), and personal predisposition, which appears to centre around conflict avoidance-a factor also noted in the research of Staats et al. (2009) and Thompson (2006). The remaining two barrier components (social and institutional support, and ease of student cheating) appear not to be associated with willingness or unwillingness to report student academic dishonesty.

In summary, while faculty generally appreciate the existence of student academic dishonesty and indicated a willingness to report such, their mixed views regarding the extent of student dishonesty seem to suggest a lack of awareness among some faculty of the pervasiveness of the problem. Overall, it appears that only psychological discomfort and cost and the lack of clear institutional procedures present significant barriers to the reporting of student academic dishonesty. The implication of this finding is that the prevalence of student academic dishonesty may be under-reported. This, in turn, may result in student academic dishonesty not being addressed within the institution.

\section{Limitations of the study}

The following limitations inherent in the study may impact on the interpretation and the generalisation of the findings:

- Research in the area of academic dishonesty is predominantly reliant on participants' responses to survey items, as was the case in the present study, and in-depth insights into the motivations behind responses are not obtained (Marsden, Carrol and Neill, 2005). Such in-depth insights might be acquired through further qualitative research, building on the issues highlighted in the current study.
- Due to the sensitivity of the issue under investigation and the desire of the researchers to safeguard participant anonymity, no information was obtained with regard to academic tenure with the university, age, or race of participants, or whether participants were primarily involved in teaching at post-graduate or under-graduate levels. It is possible that such variables may interact with academic attitudes and behaviours associated with student academic dishonesty.

- While a concerted effort was made to survey all faculty members, due to academic timetables, the possibility exists that some potential participants in the study were not reached, while others may have been unwilling to respond. While the response rate of $49 \%$ is acceptable for a survey of this nature, the fact remains that approximately half of the faculty were not surveyed, and may have held differing views. Coupled with this limitation, the study was conducted at only one university. These facts must be borne in mind when extrapolating the findings.

\section{CONCLUSION}

Emanating from the findings, recommendations are furnished to the university at which the study was undertaken in an endeavour to promote the addressing of student academic dishonesty and the development of future ethical members and leaders of society.

- If the institution wishes to address student academic dishonesty, such dishonesty must be identified, reported, and dealt with. Accordingly, the psychological discomfort of and costs to faculty that pose a barrier to reporting need to be recognised. The facet of psychological discomfort may be difficult to address as, at least in part, it may be due to a personality disposition related to conflict avoidance. The second facet appears to relate to work volume and, in this regard, consideration should be given to minimising the bureaucracy associated with dealing with student academic dishonesty and the structuring of workloads to allow time for implementing measures to prevent and take action against student academic dishonesty. Such action would also address the barrier component associated with ease of student cheating, although the component was not shown to be directly associated with the reporting or not of student academic dishonesty.

- While the university has instituted policies and guidelines to address student academic dishonesty, it is essential that such policies and guidelines are translated into active processes, and applied within the different faculties and departments to ensure that a single 'institutional message' is sent to students, and that student academic dishonesty is consistently reported and addressed across faculties and departments. In this regard, it should be reinforced with faculty that, as part 
of their overall work compact, they are required to be vigilant with regard to student academic dishonesty in the interests of protecting the integrity of academia. Iyer and Eastman (2006) note the importance of gaining faculty support for and understanding of academic integrity policies and honour codes, and stress that such support and understanding impact the actions of faculty in taking action against student academic dishonesty.

- Participants perceived that $10 \%$ of faculty themselves engage in acts of academic dishonesty. Similar findings of faculty dishonesty have been reported internationally (cf. Bruhn, Zajac, Al-Kazemi and Prescott, 2002). However, even a low incidence of such behaviour can be damaging to the development of an ethical academic culture and impact the prevention of student academic dishonesty and related actions. Williams and Dewett (2005) propose that students' moral and ethical development rely on the context within which they occur, i.e. the university. Accordingly, Johnson and Clerehan (2005) advocate the development of 'ethical communities' at universities, and Hughes and McCabe (2006, p. 58) suggest that academic integrity needs to be supported "by the development of systems and a campus climate or culture that demands integrity by all members of the university community."

Building on this study, future research in this area could include pursuing qualitative research within the same university and others in South Africa in order to gain a deeper understanding of the personal and institutional barriers that discourage action to address student academic dishonesty. In particular, research that uncovers the factors associated with faculty's psychological discomfort as a barrier to reporting and addressing student academic dishonesty may be fruitful. In addition, research should probe the underlying institutional assumptions regarding student academic dishonesty and the role that such assumptions play in dealing with this problem, including their impact on consistency in the way policies are enacted.

The extent of student academic dishonesty has been firmly established in the literature. Accordingly, universities and their faculties should be proactive in establishing organisational cultures, along with supportive structures and systems, that address this threat to academic integrity. Understanding faculty's attitudes and individual and institutional barriers to taking action in respect of student academic dishonesty is a first step in this journey.

\section{ACKNOWLEDGMENTS}

The authors would like to express their sincere appreciation to the Faculty of Management at the University of Johannesburg for the grant that covered the costs of the field work and to the following research assistants: Bradley Britz, Cari du Toit, Sheena Groenewald, Nick Stroucken, and Jono Terry. Further thanks are also extended to Sheena Groenewald who assisted in sourcing information for the literature review.

\section{REFERENCES}

Bertram-Gallant, T. (2007). The complexity of integrity culture change: A case study of a liberal arts college, Review of Higher Education, 30 (4), 391-411.

Bertram-Gallant, T. (2008). Twenty-first century forces shaping academic integrity, ASHE Higher Education Report, 33 (5), 65-78.

Bisping, T.O., Patron, H. and Roskelley, K. (2008). Modeling academic dishonesty: The role of student perceptions and misconduct type, Journal of Economic Education, 39 (1), 4-21.

Bok, D. (2003). Universities in the marketplace: The commercialization of postsecondary education. Princeton, NJ: Princeton University Press.

Borkowski, S.C. and Welsh, M.J. (1998). Ethics and the accounting publishing process: Author, review, and editor issues, Journal of Business Ethics, 17, 1785-1803.

Born, A.D. (2003). How to reduce plagiarism, Journal of Information Systems Education, 14 (3), 223-224.

Brimble, M. and Stevenson-Clarke, P. (2006). Managing academic dishonesty in Australian universities: Implications for teaching, learning and scholarship, Accounting, Accountability and Performance, 12 (1), 32-63.

Bruhn, J.G., Zajac, G., Al-Kazemi, A.A. and Prescott, L.D. Jr. (2002). Moral positions and academic conduct: Parameters of tolerance for ethics failure, Journal of Higher Education, 73 (4), 461-493.

Brown, C.A., Dickson, R., Humphreys, A.L., McQuillan, V. and Smears, E. (2008). Promoting academic writing/referencing skills: Outcome of an undergraduate e-learning pilot project, British Journal of Educational Technology, 39 (1), 140-156.

Coalter, T., Lim, C.L. and Wanorie, T. (2007). Factors that influence faculty actions: A study on faculty responses to academic dishonesty, International Journal for the Scholarship of Teaching and Learning, 1 (1), 1-19.

Conroy, S. and Emerson, T. (2004). Business education and religion: Religiosity as a predictor of ethical awareness among students, Journal of Business Ethics, 50, 383-396.

Cooper, M. and Schwartz, R. (2007). Moral judgment and student discipline: What are institutions teaching? What are students learning? Journal of College Student Development, 48 (5), 595-607.

De Bruin, G.P. and Rudnick, H. (2007). Examining the cheats. The role of conscientiousness and excitement seeking in academic dishonesty, South African Journal of Industrial Psychology, 37 (1), 153-164.

Eastman, J.K., lyer, R. and Eastman, K.L. (2006). Addressing academic dishonesty: The implications for business schools, professors and students, Journal for Advancement of Marketing Education, 9(Winter), 1-8.

Elander, J., Pittam, G., Lusher, J., Fox, P. and Payne, N. (2010). Evaluation of an intervention to help students avoid unintentional plagiarism by improving their authorial identity, Evaluation in Higher Education, 35 (2), 490-501.

Garofalo, C. (2003). Toward a global ethic: Perspectives on values, training and moral agency, The International Journal of Public Sector Management, 16 (7), 490-501.

Gbadamosi, G. (2004). Academic ethics: What has morality, culture and administration got to do with its measurement?, Management Decision, 42 (9), 1145-1161.

Gorsuch, R.L. (1983). Factor analysis (2 ${ }^{\text {nd }}$ edition). Englewood Cliffs, NJ: Erlbaum.

Hard, S.F., Conway, J.M. and Moran, A.C. (2006). Faculty and college student beliefs about the frequency of student academic misconduct, The Journal of Higher Education, 77 (6), 1058-1080.

Hughes, J.M.C. and McCabe, D.L. (2006). Understanding academic misconduct, The Canadian Journal of Higher Education, 36 (1), 49-63.

Hutton, P.A. (2006). Understanding student cheating and what educators can do about it, College Teaching, 54 (1), 171-176.

lyer, R. and Eastman, J.K. (2006). Academic dishonesty: Are business students different from other college students?, Journal of Education for Business, November/December, 101-109. 
Johnson, A and Clerehan, R. (2005). A rheme of one's own: How 'original' do we expect students to be?, Journal of University Teaching and Learning Practice, 2 (3a), [Online]. Available: http://jut|p.uow.edu.au/2005_v02_i03a/ pdf. Accessed on 27 March 2008.

Kelley, P.C. and Chang, P.L. (2007). A typology of university ethical lapses: Types, levels of seriousness, and originating location, The Journal of Higher Education, 78 (4), 402-429.

Kidwell, L.A, Woziak, K. and Laurel, J.P. (2003). Student reports and faculty perceptions of academic dishonesty, Teaching Business Ethics, 7, 205-214. Kiehl, E.M. (2006). Using an ethical decision-making model to determine consequences for student plagiarism, Journal of Nursing Education, $45(6), 199-203$.

Lahm, R.J. (2007). Plagiarism and business plans: A growing challenge for entrepreneurship, Journal of Entrepreneurship Education, 10, 73-84. Larkham, P.J. and Manns, S. (2002). Plagiarism and its treatment in higher education, Journal of Further and Higher Education, 26 (4), 339-349.

Lee, D.E. (2009). Cheating in the classroom: Beyond policing, The Clearing House, March/April, 171-174.

Lehobye, N.M. (2010). Plagiarism: Misconduct awareness on novice research within the cyberworld, Potchefstroom Electronic Law Journal, 13 (3), 494-508.

Lewellyn, P.A.G. (1996). Academic perceptions: Ethics in the information systems discipline, Journal of Business Ethics, 15, 559-569.

Marsden, H., Carroll, M. and Neill, J. (2005). Who cheats at university? A self-report study of dishonest academic behaviours in a sample of Australian university students, Australian Journal of Psychology, 57 (1), 1-10.

Martin, D.E., Rao, A. and Sloan, L.R. (2009). Plagiarism, integrity and workplace deviance: A criterion study, Ethics and Behavior, 19 (1), 36-50. Mullins, A. (2000). Cheating to win, University Affairs, December, 22-28. O'Rourke, J., Barnes, J., Deaton, A., Fulks, K., Ryan, K. and Rettinger, D.A. (2009). Imitation is the sincerest form of cheating: The influence of direct knowledge and attitudes on academic dishonesty, Ethics and Behavior, 20 (1), 47-64.

Parameswaran, A. and Devi, P. (2006). Student plagiarism and faculty responsibility in undergraduate engineering labs, Higher Education Research and Development, 25 (3), 263-276.

Park, C. (2003). In other (people's) words: Plagiarism by university students - literature and lessons, Assessment and Evaluation in Higher Education, 28, 471-488.

Puka, B. (2005). Student cheating, Liberal Education, Summer/Fall, 32-35.
Rawwas, M.Y.A. and Isakson, H.R. (2000). Ethics of tomorrow's business managers, Journal of Education for Business, 75 (6), 321-331.

Robie, C. and Kidwell, R.E. (2003). The 'ethical' professor and the undergraduate student: Current perceptions of moral behavior among business school faculty, Journal of Academic Ethics, 1, 153-173.

Robinson, E., Amburgey, R. Swank, E. and Faulkner, C. (2004). Test cheating in a rural college: Studying the importance of individual and situational factors, College Student Journal, 38 (3), 380-395.

Schmelkin, L.P., Gilbert, K., Spencer, K.J., Pincus, H.S. and Silva, R. (2008). A multidimensional scaling of college students' perceptions of academic dishonesty, The Journal of Higher Education, 79 (5), 587-607.

Smith-Gratto, K. and Jost, M. (2007). An academic dishonesty dilemma: A case study, Academic Exchange, Summer, 36-41.

Staats, S., Hupp. J.M., Wallace, H. and Gresley, J. (2009). Heroes don't cheat: An examination of academic dishonesty and students' views on why professors don't report cheating, Ethics and Behavior, 19 (3), 171-183. Teodorescu, D. and Andrei, T. (2009). Faculty and peer influences on academic integrity: College cheating in Romania, Higher Education, 57, 267-282.

Thompson, C.C. (2006). Unintended lessons: Plagiarism and the university, Teachers College Record, 108 (12), 2439-2449.

University of Johannesburg. (2008). Report on the 2008 research outputs. Johannesburg: University of Johannesburg.

Valentine, S. and Kidwell, R.E. (2008). Business students' ethical evaluations of faculty misconduct, Quality Assurance in Education, 16 (3), 287-300.

Volpe, R., Davidson, L. and Bell, M.C. (2008). Faculty attitudes and behaviors concerning student cheating, College Student Journal, 42 (1), 164-175.

Warren, B.W. and Rosenthal, D. (2006). Teaching business ethics - Is it a lost cause?, International Journal of Management, 23 (3), 679-698.

Williams, M.S. and Hosek, W.R. (2003). Strategies for reducing academic dishonesty, Journal of Legal Studies Education, 21, 87-92.

Williams, S.D. and Dewett, T. (2005). Yes, you can teach business ethics: A review and research agenda, Journal of Leadership and Organizational Studies, 12 (2), 109-120.

How to cite this article: Thomas A, De Bruin GP. Student academic dishonesty: What do academics think and do, and what are the barriers to action? Afr J Bus Ethics 2012;6:13-24.

Source of Support: Nil, Conflict of Interest: None declared

\section{AUTHORS}

Adèle Thomas is a Professor in the Department of Industrial Psychology and People Management at the University of Johannesburg. Her research interests include business ethics, corporate governance, corporate social responsibility and governance in universities.

Gideon de Bruin is a Professor in the Department of Industrial Psychology and People Management at the University of Johannesburg. His research interests include career counselling, professional development, and student development. 
Reproduced with permission of the copyright owner. Further reproduction prohibited without permission. 